\title{
Cognitive impairment and memory dysfunction after a stroke diagnosis: a post-stroke memory assessment
}

\author{
Noor Kamal Al-Qazzaz',5 \\ Sawal Hamid Ali' \\ Siti Anom Ahmad ${ }^{2}$ \\ Shabiul Islam ${ }^{3}$ \\ Khairiyah Mohamad ${ }^{4}$ \\ 'Department of Electrical, \\ Electronic and Systems Engineering, \\ Faculty of Engineering and Built \\ Environment, Universiti Kebangsaan \\ Malaysia, Bangi, Selangor, Malaysia; \\ ${ }^{2}$ Department of Electrical and \\ Electronic Engineering, Faculty \\ of Engineering, Universiti Putra \\ Malaysia, Serdang, Selangor, Malaysia; \\ ${ }^{3}$ Institute of Microengineering and \\ Nanoelectronics (IMEN), Universiti \\ Kebangsaan Malaysia, Bangi, \\ Selangor, Malaysia; ${ }^{4}$ Neurology Unit, \\ Department of Medicine, Universiti \\ Kebangsaan Malaysia Medical \\ Center, Cheras, Kuala Lumpur, \\ Malaysia; ${ }^{5}$ Department of Biomedical \\ Engineering, Al-Khwarizmi College \\ of Engineering, Baghdad University, \\ Baghdad, Iraq
}

This article was published in the following Dove Press journal:

Neuropsychiatric Disease and Treatment

9 September 2014

Number of times this article has been viewed

\begin{abstract}
Cognitive impairment and memory dysfunction following stroke diagnosis are common symptoms that significantly affect the survivors' quality of life. Stroke patients have a high potential to develop dementia within the first year of stroke onset. Currently, efforts are being exerted to assess stroke effects on the brain, particularly in the early stages. Numerous neuropsychological assessments are being used to evaluate and differentiate cognitive impairment and dementia following stroke. This article focuses on the role of available neuropsychological assessments in detection of dementia and memory loss after stroke. This review starts with stroke types and risk factors associated with dementia development, followed by a brief description of stroke diagnosis criteria and the effects of stroke on the brain that lead to cognitive impairment and end with memory loss. This review aims to combine available neuropsychological assessments to develop a post-stroke memory assessment (PSMA) scheme based on the most recognized and available studies. The proposed PSMA is expected to assess different types of memory functionalities that are related to different parts of the brain according to stroke location. An optimal therapeutic program that would help stroke patients enjoy additional years with higher quality of life is presented.
\end{abstract}

Keywords: dementia, vascular dementia, memory, neuropsychological assessment

\section{Introduction}

Cognitive impairment and memory loss are common after a stroke. Approximately $30 \%$ of stroke patients develop dementia within 1 year of stroke onset. ${ }^{1}$ Stroke affects the cognitive domain, which includes attention, memory, language, and orientation. The most affected domains are attention and executive functions; at the time of stroke diagnosis, memory problems are often prominent. Post-stroke dementia (PSD), particularly vascular dementia $(\mathrm{VaD})$, reflects the vascular risk factors that are mostly correlated with cerebral vascular disease (CVD). Post-stroke cognitive impairment is the evolution of CVD that predisposes individuals to the vascular cognitive impairment (VCI) spectrum. Thus, understanding the VCI spectrum stages is necessary to evaluate the mental state of post-stroke patients, particularly the cognitive dysfunction and memory decline during the period following a stroke diagnosis. Until recently, no specific neuropsychological assessment to evaluate PSD including memory loss existed. Current efforts are focused on combining more than one of the available neuropsychological assessments to obtain a significant diagnosis of cognitive decline severity following a stroke. The aim of this study was to develop a post-stroke memory assessment (PSMA) based on the most popular and available neuropsychological assessments. The proposed PSMA is expected to assess different types of memory functionalities
Correspondence: Noor Kamal Al-Qazzaz Department of Electrical, Electronic and Systems Engineering, Faculty of Engineering and Built Environment, Universiti Kebangsaan Malaysia, Bangi, Selangor 43600, Malaysia

Email noorbmemsc@siswa.ukm.edu.my
Neuropsychiatric Disease and Treatment 2014:10 1677-1691 1677

Dovepress

http://dx.doi.org//0.2147/NDT.S67184 (c) (i) (9) 2014 Al-Qazzaz et al. This work is published by Dove Medical Press Limited, and licensed under Creative Commons Attribution - Non Commercial (unported, v3.0) BY NC License. The full terms of the License are available at http://creativecommons.org/licenses/by-nc/3.0/. Non-commercial uses of the work are permitted without any further permisson how to request permission may be found at: http://www.dovepress.com/permissions.php 
that are related to different parts of the brain according to the affected memory. Results are then correlated and related to the stroke location and severity. PSMA may provide a promising tool for evaluating post-stroke $\mathrm{VaD}$ and assisting medical doctors and clinicians in the assessment as well as evaluation of post-stroke memory impairment severity.

\section{Stroke types}

Stroke is considered a major cause of long-term physical disabilities in adults; it is the second most common cause of cognitive impairment and dementia and the third leading cause of death after coronary artery diseases and cancer. ${ }^{2,3}$

A stroke is a "brain attack" that is caused either by reducing blood and oxygen flow to the brain or by bleeding. Stroke can be classified into two main types: ischemic and hemorrhagic. Transient ischemic attack (TIA) is sometimes considered as the third type of stroke and can be referred to as a "mini-stroke." Stroke characteristics are listed in Table 1.

\section{Vascular risk factors and stroke diagnosis criteria}

Numerous risk factors band to cause a stroke: modifiable risk factors, including age, sex, ethnicity, genetics; and non-modifiable risk factors, including CVD, heart disease, diabetes mellitus, hyperlipidemia, cigarette smoking, and alcohol abuse, as shown in Figure 1.5,6 Stroke, which is considered a CVD, is an influential risk factor for cognitive impairment that eventually leads to the development of PSD. ${ }^{7}$ Thus, stroke survivors require immediate medical control of these risk factors, which are modifiable, to reduce stroke prevalence.

Clinically, stroke can usually be diagnosed through typical symptoms and signs. Medical history is an early step of diagnosis and includes stroke onset, course, and patient information taken from patients' careers or relatives, followed by physical and neurological examinations of the patients. The neurological examination can be performed using the formal stroke scale developed by the National Institution of Health Stroke $\mathrm{Scale}^{8}$ to classify early stroke severity. Laboratory testing is the next step; at this stage, blood tests are used to determine the blood sugar level and cholesterol level. This step is followed by an examination of the computer tomography/ magnetic resonance imaging scan and electrocardiography recording to indicate stroke location and pulse irregularity, such as cardiovascular status, carotid bruits, fundus examination, peripheral vascular disease, and hypertension. ${ }^{9}$ Electroencephalography is used to help differentiate between seizure and TIA or between lacunar and cortical infarction in occasional patients, as illustrated in Figure 2. ${ }^{10}$

\section{Stroke effects on brain cerebrovascular function}

The brain requires a constant supply of blood to carry oxygen and nutrients to the cortical neurons in order for it to function in a normal manner. Numerous arteries cooperate to achieve this demand. In the case where an ischemic or hemorrhagic stroke occurs in one or more of these arteries and/or their branches, it causes damage to a specific neuroanatomic location (ie, right hemisphere cortex, left hemisphere cortex, or subcortex, which can then be localized further to the frontal lobe, temporal lobe, parietal lobe, thalamus, for example). Thus, the part of the brain that does not get the blood it needs starts to die. Brain cellular damage and death within minutes of stroke onset is called the core, whereas the zone in which the blood decreases or marginal perfusion occurs is called the ischemic penumbra, as shown in Figure 3. ${ }^{4,11}$

Owing to the complexity of the neuronal networks concerned in cortical processes, the ischemic or hemorrhagic stroke that occurs in a specific vascular distribution and the damage to a neuroanatomic site typically impairs more than one cognitive function. Moreover, some stroke events may involve multiple neurologic systems that cause cognitive decline based on vascular distribution (ie, perceptual and sensory or motor and sensory), as tabularized in Table 2. ${ }^{12}$

Table I Classification of stroke

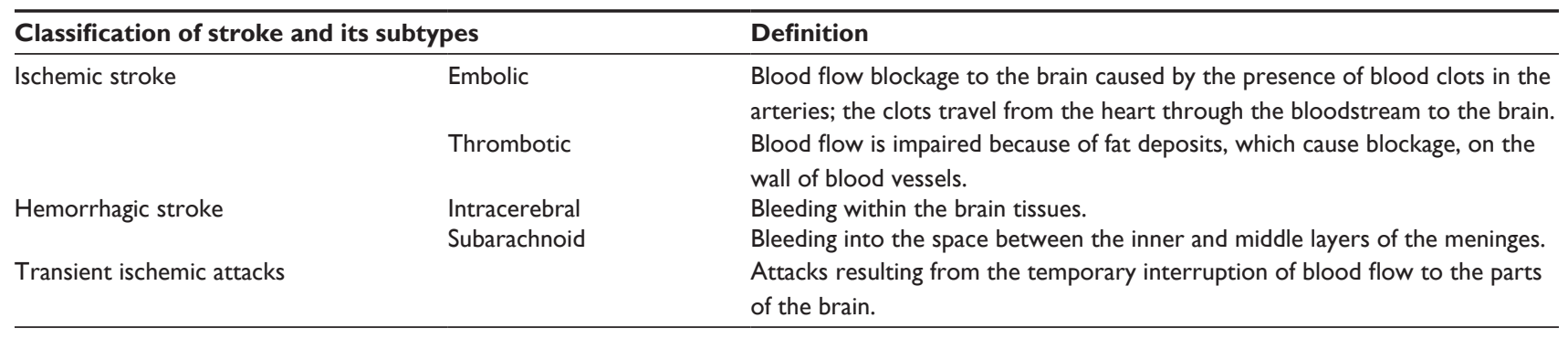




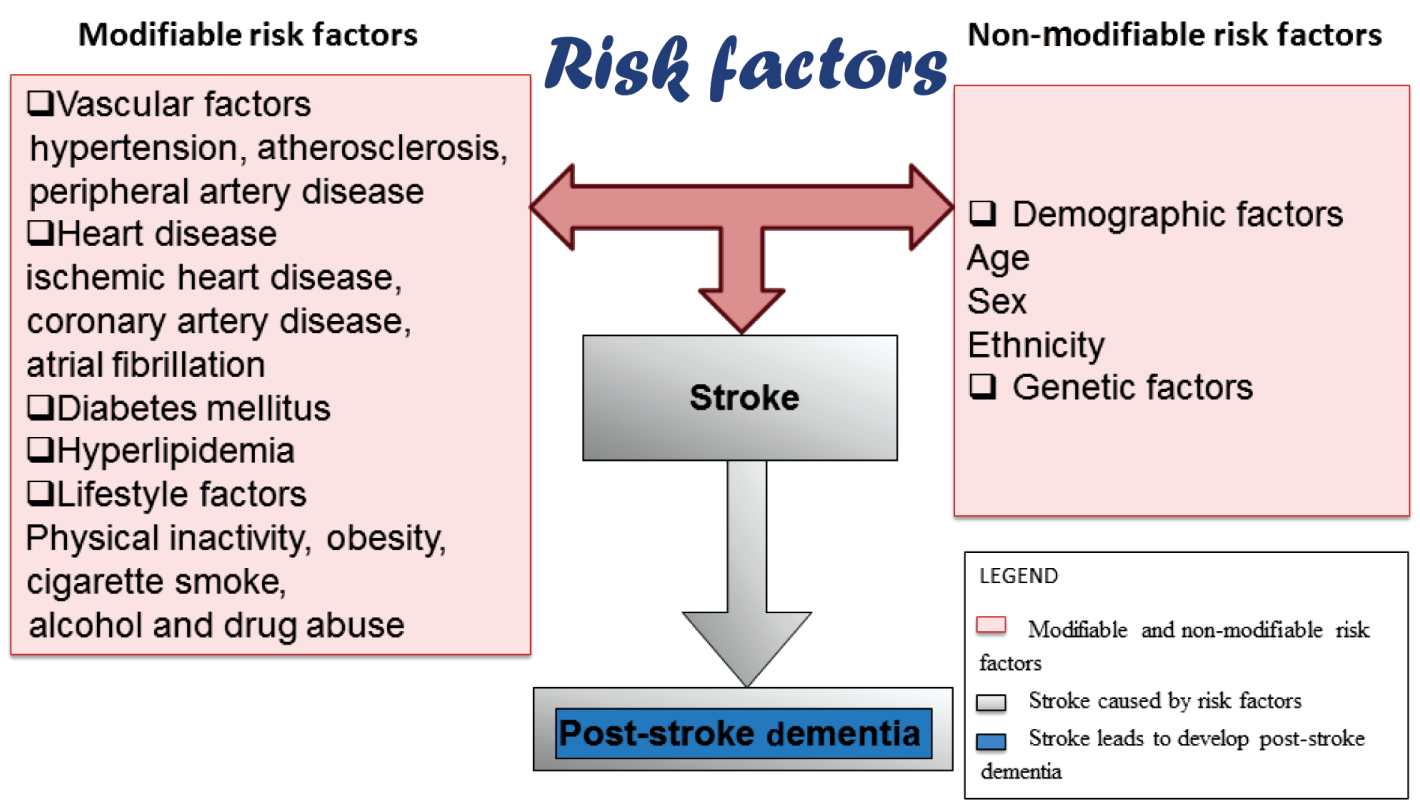

Figure I Risk factors and dementia.

\section{Cognitive disorder following a stroke}

Dementia is associated with neurodegenerative disorder diversity, neuronal dysfunction, and neuronal death. Dementia occurs when the brain is affected by a specific disease or condition that causes cognitive impairment. ${ }^{13}$ In the case of a stroke, one or more cognitive domains may be affected, including attention, memory, language, and orientation. The highest impact of stroke at the time of diagnosis is on the attention and executive functions rather than on memory, which may be impaired at various post-stroke intervals. Previous studies show that post-stroke memory prevalence varies from $23 \%$ to $55 \% 3$ months after stroke, ending with a decline from $11 \%$ to $31 \% 1$ year after stroke onset. ${ }^{3,14}$ Cognitive impairment after a stroke is common and leads to PSD. PSD includes all dementia types that occur after a stroke, including $\mathrm{VaD}$; degenerative dementia, particularly Alzheimer's disease (AD); or mixed dementia (VaD plus $\mathrm{AD}) .{ }^{2} \mathrm{VaD}$, the second leading cause of dementia in the world after $\mathrm{AD}$, occurs as a result of stroke. Between $1 \%$ and $4 \%$ of elderly people aged 65 years and older suffer from $\mathrm{VaD}$, and its prevalence will double every 5-10 years after this age. ${ }^{15,16} \mathrm{VaD}$ is characterized by impairment in the cognitive function due to vascular lesion and infarction resulting from the stroke. The clinical manifestation of $\mathrm{VaD}$ varies based on the size, location, and type of cerebral damage. ${ }^{15}$ Figure 4 illustrates the cognitive impairment sequences which predispose individuals to the VCI spectrum.

The VCI spectrum can be viewed as a cognitive consequence in the cognitive domain, starting from mild cognitive impairment (MCI) and ending with severe dementia. The period beyond dementia in which the brain is at risk is called "cognitive impairment no dementia." 17

MCI causes a more considerable decline in cognitive function with respect to individual age and education level, but not notably with the activities of daily life. ${ }^{18,19}$ Clinically, $\mathrm{MCI}$ is the transitional stage between early normal cognition and late severe dementia, and it is considered heterogeneous because some MCI patients develop dementia while others stay and continue as MCI patients for many years. However, by default, patients diagnosed with MCI have a high

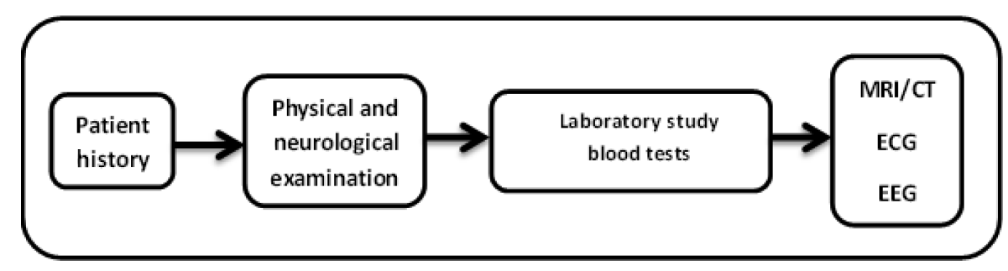

Figure 2 Clinical evaluation.

Abbreviations: CT, computed tomography; ECG, electrocardiography; EEG, electroencephalography; MRI, magnetic resonance imaging. 


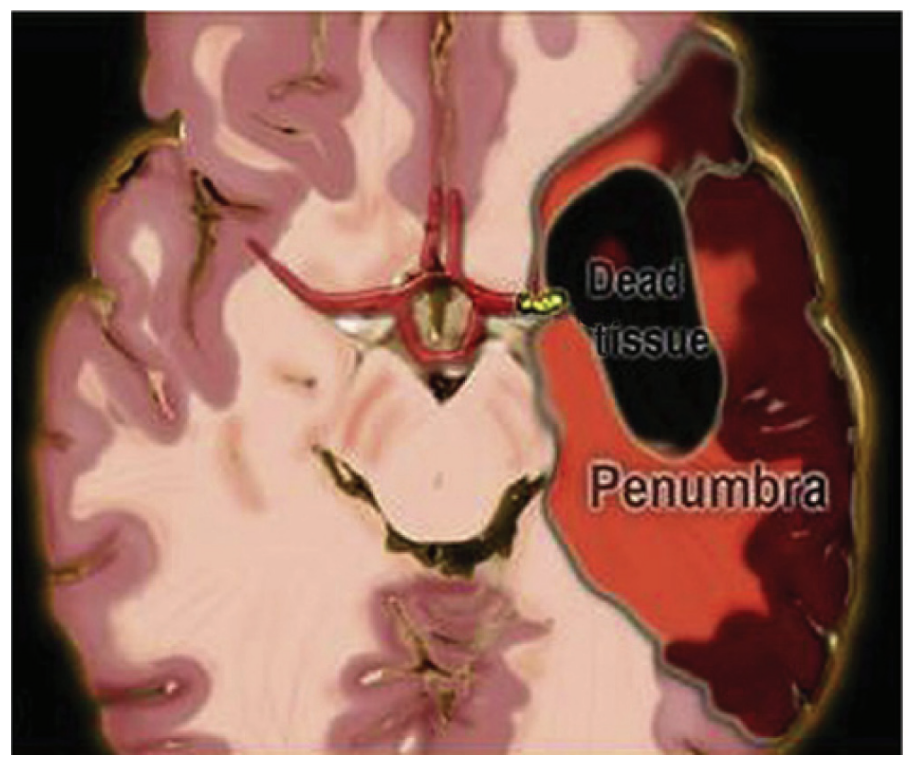

\section{LEGEND}

Normal brain tissues

Penumbra region

Dead tissue region

Figure 3 Core and penumbra after stroke.

Note: Reprinted from Journal of Radiology Nursing, 30(3), Summers D, Malloy R, CT and MR imaging in the acute ischemic stroke patient: a nursing perspective, I04-II5, Copyright 2011, with permission from Elsevier. ${ }^{56}$

Table 2 Stroke outcome due to vessel infarction

\begin{tabular}{|c|c|}
\hline Brain artery infarction & Stroke outcome \\
\hline \multirow[t]{7}{*}{ Left middle cerebral artery } & Aphasia \\
\hline & Mutism \\
\hline & Buccofacial apraxia \\
\hline & Agraphia \\
\hline & Acalculia \\
\hline & Ideational apraxia \\
\hline & Right/left confusion \\
\hline \multirow[t]{7}{*}{ Right middle cerebral artery } & Neglect (personal, extrapersonal, and representational) \\
\hline & Visuospatial failures and visuoconstructive disorders \\
\hline & Aprosodia \\
\hline & Language usage (pragmatic language) \\
\hline & Disorders \\
\hline & Anosognosia \\
\hline & Anosodiaphoria \\
\hline \multirow[t]{6}{*}{ Posterior cerebral artery } & Color agnosia \\
\hline & Associative visual agnosia \\
\hline & Alexia (hemianopic and pure) \\
\hline & Facial agnosia \\
\hline & Bálint's syndrome \\
\hline & Amnesia \\
\hline \multirow[t]{3}{*}{ Anterior cerebral artery } & Deficits in planning, initiation, monitoring, concentration, and flexibility \\
\hline & Contralateral leg weakness \\
\hline & Sensory loss \\
\hline Subcortical infarcts & Impaired arousal, attention, motivation, initiation, and executive function \\
\hline (include thalamic infarcts) & Memory (verbal, visual, episodic declarative, anterograde, and retrograde) \\
\hline \multirow[t]{2}{*}{ Caudate infarcts } & Impaired problem solving and attention \\
\hline & Memory \\
\hline Subcortical & Confusion \\
\hline (infarcts of the inferior genu of the internal capsule) & Memory disturbance \\
\hline Subarachnoid hemorrhage & Amnesia \\
\hline \multirow[t]{3}{*}{ (anterior communicating artery aneurysm) } & Personality changes \\
\hline & Confabulation \\
\hline & Abulia due to damage to the mesial frontal cortex \\
\hline \multirow[t]{2}{*}{ Limbic and paralimbic lesion } & Implicated in a failure to learn and retain new information \\
\hline & Affective changes \\
\hline
\end{tabular}




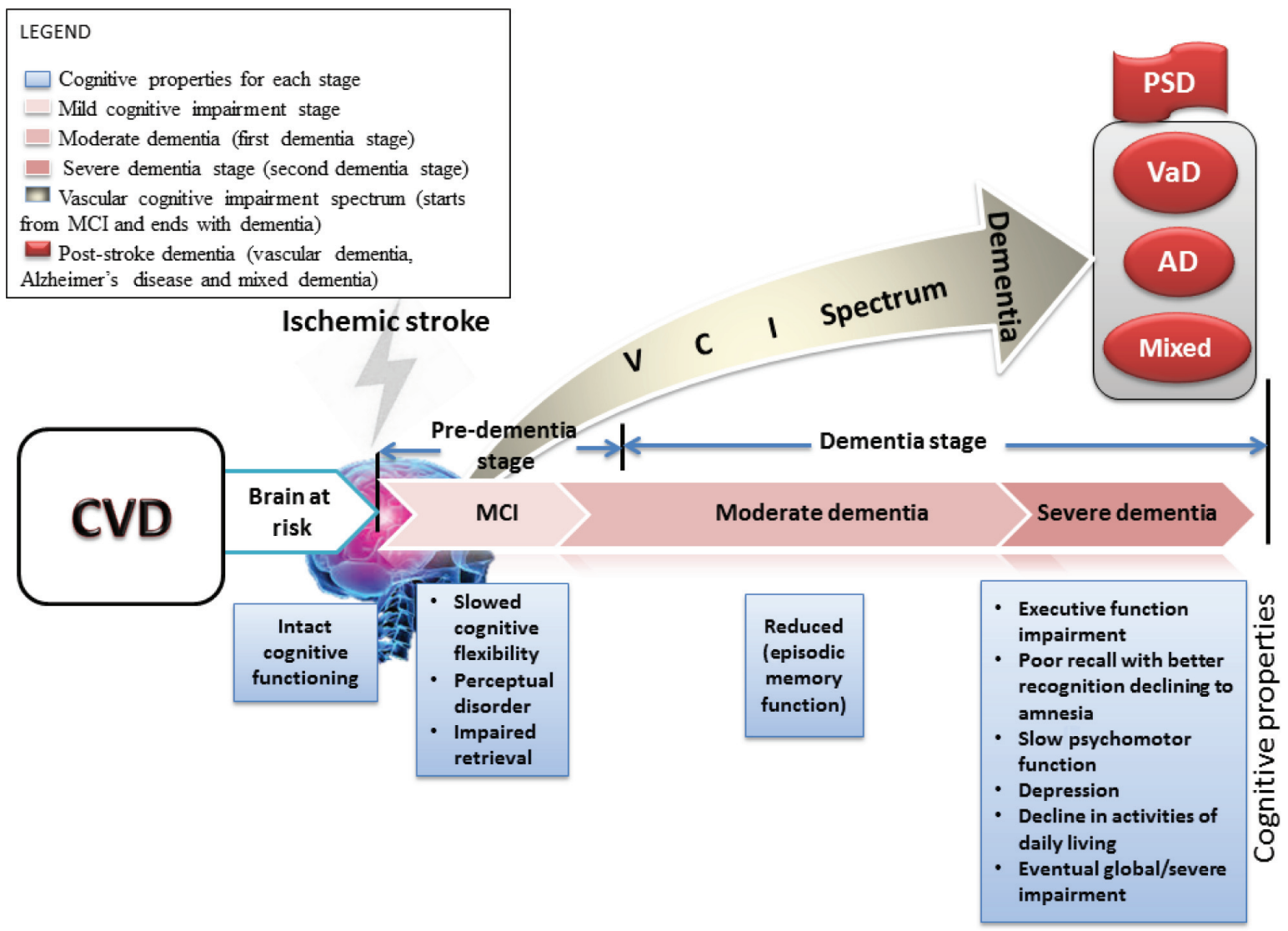

Figure 4 Block diagram of vascular cognitive impairment spectrum.

Abbreviations: AD, Alzheimer's disease; CVD, cerebral vascular disease; $\mathrm{MCl}$, mild cognitive impairment; PSD, post-stroke dementia; VaD, vascular dementia; VCl, vascular cognitive impairment.

potential to develop dementia within the third month from the time dementia symptoms begin to arise. ${ }^{2,20}$ The most observed symptoms of MCI are limited to memory, but the patient's daily living activities are preserved. ${ }^{21}$ This article is focused on $\mathrm{VaD}$ as a common cause of cognitive impairment following a stroke and the effect of $\mathrm{VaD}$ on memory loss. It likewise discusses the available neuropsychological assessments that assess and predict the effect of dementia based on the dementia spectrum as well as aids in detecting signs of dementia, particularly memory disturbance. A number of diagnosis criteria and clinical neuropsychological assessments are combined. The most common diagnosis criteria are developed and characterized by the National Institute of Neurological Disorders and Stroke and Association Internationale pour la Recherché et l'Enseignement en Neurosciences for $\mathrm{VaD}^{22-26}$ and Diagnostic and Statistical Manual of Mental Disorders, Fourth Edition criteria. ${ }^{27}$ The severity of cognitive symptoms could be assessed using the Clinical Dementia Rating Scale. ${ }^{28}$ The most usable test to evaluate the early dementia stages, even severity of dementia in clinical practice, is the Mini-Mental State Examination (MMSE). ${ }^{29}$

\section{Brain memory and causes of memory loss}

The brain memory system refers to the process of how our brain transmits and stores available information for future use, with or without conscious awareness. The human brain memory system is a complex structure, with different functionalities, as shown in Table 3. Based on stroke location and severity, memory disorder may occur for one or more memory types, eventually ending in memory decline and loss. ${ }^{30}$

Table 3 Types of memory

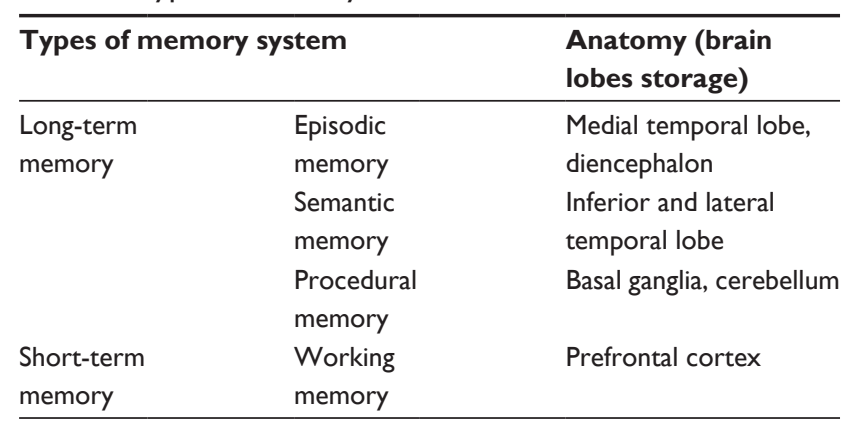


Table 4 Brain memory loss causes

\begin{tabular}{|c|c|c|}
\hline Cause of memory loss & Subcases of memory loss & Memory loss type \\
\hline Lifestyle factors & $\begin{array}{l}\text { Medication } \\
\text { Sleep pills, anti-histamine, anti-anxiety, } \\
\text { schizophrenia medication, pain medication after } \\
\text { surgery } \\
\text { Alcoholic and illicit drug use } \\
\text { Deficiency in vitamin } \mathrm{BI} \text {, change in chemical memory } \\
\text { Stress } \\
\text { Emotional trauma (chronic or short-term stress) } \\
\text { Sleep deprivation } \\
\text { Stress, insomnia, sleep apnea } \\
\text { Nutritional deficiencies } \\
\text { Loss of vitamin } \mathrm{BI} \text {, loss of vitamin } \mathrm{BI} 2 \\
\text { Marijuana consumption }\end{array}$ & $\begin{array}{l}\text { Learning } \\
\text { Memory } \\
\text { consolidation } \\
\text { LTM } \\
\text { Episodic memory }\end{array}$ \\
\hline Brain injury & $\begin{array}{l}\text { Acquired brain injury } \\
\text { Traumatic brain injury (assaults, road traffic accident, fall) } \\
\text { Non-traumatic brain injury } \\
\text { Stroke (ischemic, hemorrhagic, TIA) } \\
\text { Tumors (pediatric glial, non-glial, recurrent, metastatic, others: } \\
\text { cysts, neurofibromatosis, pseudotumor cerebri, tuberous } \\
\text { sclerosis) } \\
\text { Metabolic disorder (liver disease, kidney disease, diabetes, } \\
\text { ischemia, oxygen hypoxia to the brain, poison through ingestion } \\
\text { or inhalation of toxic substance) } \\
\text { Cognitive brain injury (present at birth) } \\
\text { Brain cognition (dementia), multiple sclerosis, Parkinson's disease }\end{array}$ & $\begin{array}{l}\text { LTM (episodic, } \\
\text { semantic) } \\
\text { STM } \\
\text { Working memory } \\
\text { Procedural memory }\end{array}$ \\
\hline Infection & HIV, tuberculosis, syphilis, herpes, encephalitis, meningitis & \\
\hline Thyroid dysfunction & Underactive, overactive & $\begin{array}{l}\text { STM } \\
\text { Working memory }\end{array}$ \\
\hline Aging & $\begin{array}{l}\text { Dehydration, normal aging } \\
\text { Depression (common with aging) }\end{array}$ & $\begin{array}{l}\text { Recall memory } \\
\text { Ability to think } \\
\text { Episodic memory } \\
\text { Procedural memory } \\
\text { Working memory }\end{array}$ \\
\hline $\begin{array}{l}\text { Mild cognitive impairment } \\
\text { Dementia }\end{array}$ & $\begin{array}{l}\text { Early stage of dementia } \\
\text { AD } \\
\text { Cortical amyloid plaques, neurofibrillary tangles } \\
\text { VaD } \\
\text { Stroke, deficiencies of (thyroid hormone, vitamin BI2, folic acid), } \\
\text { hydrocephalus, hypercalcemia } \\
\text { Mixed (AD + VaD), Lewy body disease, Parkinson's disease, } \\
\text { frontotemporal, alcoholic }\end{array}$ & $\begin{array}{l}\text { Working memory } \\
\text { Episodic memory } \\
\text { Semantic memory } \\
\text { Working memory } \\
\text { LTM } \\
\text { STM }\end{array}$ \\
\hline
\end{tabular}

Abbreviations: AD, Alzheimer's disease; HIV, human immunodeficiency virus; LTM, long-term memory; STM, short-term memory; TIA, transient ischemic attack; $\mathrm{VaD}$, vascular dementia.

Memory loss can be caused by several factors, such as lifestyle, brain injury, infection, thyroid dysfunction, aging, MCI, and dementia (Table 4). ${ }^{31}$

This article focuses on stroke as the major cause of cognitive impairment resulting in memory decline. The effect of stroke varies based on its type, location, and severity. ${ }^{2}$ After a stroke, the most prominent impairment can be recognized in the patient's processing speed, attention, and executive function. Note that $20 \%-50 \%$ of stroke patients suffer from memory intricacy that manifests during the period following a stroke diagnosis. PSD, particularly $\mathrm{VaD}$, causes slowing in cognitive flexibility, perceptual disorder, and impairment information retrieval at the time of stroke diagnosis. This period corresponds to $\mathrm{MCI}$ in the VCI spectrum, followed by a decline in episodic memory function in case of dementia, and ending in severe dementia and impairment of all cognitive properties..$^{32-35}$

\section{Cognitive domain and memory assessment after a stroke}

Cognitive impairment, particularly memory problems following a stroke, can be evaluated and assessed through neuropsychological assessments. Clinically, different neuropsychological 
assessments are used to assess cognitive dysfunction in terms of cognitive domain. ${ }^{36}$ A set of standardized neuropsychological assessments have been selected due to their sensitivity for MCI and to cover different cognitive domains including memory; for example, MMSE, ${ }^{29}$ Montreal Cognitive Assessment (MoCA), ${ }^{37}$ and Addenbrooke's Cognitive Examination Revised (ACE-R) ${ }^{38}$ are widely used to assess the cognitive dysfunction of patients. Several validated clinical neuropsychological assessments are used to assess cognitive domain, including (but not limited to) Trail Making Test (TMT) $)^{39}$ and
Clock Drawing Test $(\mathrm{CDT})^{40}$ for attention and executive function (both are short tests that evaluate executive function), ${ }^{18}$ Rey Osterrieth Figure Copy ${ }^{41}$ for construction praxis test, and Phonological and Semantic Fluency Token test for language test. ${ }^{42}$ Other tests (eg, Frontal Assessment Battery $[\mathrm{FAB}]^{43}$ ) can be used as a quick and easy battery test. The Cambridge Examination for Mental Disorders of the Elderly, ${ }^{44}$ is a standardized instrument that is used to investigate the cognitive domains required to diagnose dementia in multiple domains, including memory. The most common tests to assess memory

Table 5 Memory classification

\begin{tabular}{|c|c|c|c|c|}
\hline Type & & Test & Subtest & $\begin{array}{l}\text { Brain lesion suspected } \\
\text { location }\end{array}$ \\
\hline \multirow[t]{5}{*}{ Short-term memory } & & MMSE & Orientation, registration & Prefrontal cortex, Broca's \\
\hline & & ACE-R & Orientation, registration & area, supplementary \\
\hline & & MoCA & Orientation & motor cortex, left \\
\hline & & WMS-IV & Orientation & posterior parietal cortex, \\
\hline & & RBMT & Orientation & $\begin{array}{l}\text { right posterior parietal } \\
\text { cortex }\end{array}$ \\
\hline \multirow[t]{10}{*}{ Working memory } & & MMSE & $\begin{array}{l}\text { Attention and concentration (serial subtraction), } \\
\text { verbal (repetition of sentences), } \\
\text { visuo-spatial ( } 2 \text { pentagons drawing) }\end{array}$ & $\begin{array}{l}\text { Prefrontal cortex, } \\
\text { dorsolateral prefrontal } \\
\text { cortex }\end{array}$ \\
\hline & & ACE-R & $\begin{array}{l}\text { Attention and concentration (serial subtraction), } \\
\text { verbal (language repetition), } \\
\text { visuo-spatial ( } 2 \text { pentagons and cube drawing), } \\
\text { perceptual ability (dot counting and letters identifying) }\end{array}$ & \\
\hline & & MoCA & $\begin{array}{l}\text { Attention and concentration (forward and backward } \\
\text { list of digits), verbal (language repetition), visuo-spatial } \\
\text { (cube drawing) }\end{array}$ & \\
\hline & & TMT $A$ and $B$ & Attention and concentration & \\
\hline & & Stroop test & Attention and concentration (color test) & \\
\hline & & WCST & Executive function & \\
\hline & & CDT & Visuospatial & \\
\hline & & WMS-IV & Visual working memory (spatial addition, spatial span) & \\
\hline & & WAIS-IV & Digit span (attention, concentration and mental control) & \\
\hline & & & $\begin{array}{l}\text { Arithmetic (concentration while manipulating mental } \\
\text { mathematical problems) }\end{array}$ & \\
\hline \multirow[t]{13}{*}{ Long-term memory } & Episodic & MMSE & Recall three objects & Medial temporal lobe, \\
\hline & memory & ACE-R & Recall three objects/anterograde, retrograde & diencephalon \\
\hline & & MoCA & Delayed recall & \\
\hline & & WMS-IV & Delayed memory (logical memory II) & \\
\hline & & RBMT & Delayed recall & \\
\hline & Semantic & MMSE & Language repetition, naming, comprehension & Inferior and lateral \\
\hline & memory & ACE-R & $\begin{array}{l}\text { Verbal fluency, language repetition, naming, } \\
\text { comprehension, reading, writing }\end{array}$ & temporal lobe \\
\hline & & MoCA & Verbal fluency, language repetition, naming & \\
\hline & & $\mathrm{FAB}$ & Verbal fluency & \\
\hline & & WMS-IV & Verbal fluency & \\
\hline & & RBMT & Verbal fluency & \\
\hline & & CVLT & Verbal fluency & \\
\hline & $\begin{array}{l}\text { Procedural } \\
\text { memory }\end{array}$ & RBMT & & Basal ganglia, cerebellum \\
\hline
\end{tabular}

Abbreviations: ACE-R, Addenbrooke's Cognitive Examination - Revised; CDT, Clock Drawing Test; CVLT, California Verbal Learning Test; FAB, Frontal Assessment Battery Scale; MMSE, Mini-Mental State Examination; MoCA, Montreal Cognitive Assessment; RBMT, Rivermead Behavioural Memory Test; TMT, Trail Making Test; WAIS, Wechsler Adult Intelligence Scale; WCST, Wisconsin Card Sorting Test; WMS-IV, Wechsler Memory Scale - 4th edition. 
Table 6 Neuropsychological assessment characteristics

\begin{tabular}{|c|c|c|c|c|}
\hline Assessments & Items & Subtests & Maximum score & Characteristics \\
\hline \multirow[t]{10}{*}{ MMSE } & Orientation & Orientation to place and time & 10 & Time 10 minutes \\
\hline & Registration & Repeat "ball, flag, tree" & 3 & \\
\hline & $\begin{array}{l}\text { Calculation/ } \\
\text { WORLD }\end{array}$ & $\begin{array}{l}\text { Serial } 7 \text { subtraction/WORLD } \\
\text { backward }\end{array}$ & 5 & \\
\hline & Memory recall & Recall "ball, flag, tree" & 3 & \\
\hline & Language naming & $\begin{array}{l}\text { Name of two objects (a watch } \\
\text { and a pen) }\end{array}$ & 2 & \\
\hline & $\begin{array}{l}\text { Language } \\
\text { comprehension }\end{array}$ & $\begin{array}{l}\text { "Close your eyes," "Pick up the } \\
\text { paper in your right hand, fold it in } \\
\text { half, and set it on the floor" }\end{array}$ & 3 & \\
\hline & Language writing & Write a sentence & I & \\
\hline & Language repetition & Repeat "No ifs, ands, or buts" & 1 & \\
\hline & Visuo-spatial abilities & Draw two pentagons & I & \\
\hline & MMSE total score & & 30 & \\
\hline \multirow[t]{19}{*}{ ACE-R } & Orientation* & Orientation to place and time & 10 & Time $15-20$ minutes \\
\hline & Registration* & Repeat "lemon, key, ball" & 3 & \\
\hline & $\begin{array}{l}\text { Calculation/ } \\
\text { WORLD* }\end{array}$ & $\begin{array}{l}\text { Serial } 7 \text { subtraction/WORLD } \\
\text { backward }\end{array}$ & 5 & \\
\hline & Recall* & Recall "apple, table, penny” & 3 & \\
\hline & Anterograde & $\begin{array}{l}\text { Repeat name and address, best of } \\
\text { three trials }\end{array}$ & 7 & \\
\hline & Retrograde memory & $\begin{array}{l}\text { Current prime minister, last } \\
\text { prime minister, current US } \\
\text { president, last US president }\end{array}$ & 4 & \\
\hline & Letter fluency** & No of words in I minute & 7 & \\
\hline & Category fluency & No of animals in I minute & 7 & \\
\hline & Comprehension* & $\begin{array}{l}\text { Obey written instruction "close } \\
\text { your eyes," perform three-step } \\
\text { command }\end{array}$ & 4 & \\
\hline & Writing* & Write a sentence & 1 & \\
\hline & Repetition* & $\begin{array}{l}\text { Repeat "hippopotamus, } \\
\text { eccentricity, unintelligible, } \\
\text { statistician," "above, beyond, and } \\
\text { below," and "no ifs, ands, or buts" }\end{array}$ & 4 & \\
\hline & Naming* & $\begin{array}{l}\text { Confrontation naming ( } 12 \text { line } \\
\text { drawings) }\end{array}$ & 12 & \\
\hline & $\begin{array}{l}\text { Picture } \\
\text { comprehension }\end{array}$ & $\begin{array}{l}\text { For example, "point to the object } \\
\text { with a nautical connection" }\end{array}$ & 4 & \\
\hline & Reading & Read list of five words & I & \\
\hline & Visuoexecutive* & $\begin{array}{l}\text { Intersecting pentagons, cube, and } \\
\text { clock drawing }\end{array}$ & 8 & \\
\hline & Visuoperceptual & $\begin{array}{l}\text { Dot counting without pointing, } \\
\text { recognition of fragmented letters }\end{array}$ & 8 & \\
\hline & Address recall & $\begin{array}{l}\text { Recall of name and address } \\
\text { learned earlier }\end{array}$ & 7 & \\
\hline & Address recognition & $\begin{array}{l}\text { Recognition of name and } \\
\text { address items (if not recalled } \\
\text { spontaneously) }\end{array}$ & 5 & \\
\hline & ACE-R total score & & 100 & \\
\hline \multirow[t]{2}{*}{$\mathrm{MoCA}$} & Visuoexecutive* & $\begin{array}{l}\text { Trail B test, cube copy, clock } \\
\text { drawing }\end{array}$ & 5 & Time $10-15$ minutes \\
\hline & Naming* & $\begin{array}{l}\text { Confrontation naming (lion, } \\
\text { hippo, camel) }\end{array}$ & 3 & \\
\hline
\end{tabular}

(Continued) 
Table 6 (Continued)

\begin{tabular}{|c|c|c|c|c|}
\hline Assessments & Items & Subtests & Maximum score & Characteristics \\
\hline & Digit span & $\begin{array}{l}\text { Forward (five digits), backward } \\
\text { (three digits) }\end{array}$ & 2 & \\
\hline & Attention & $\begin{array}{l}\text { Tapping at the letter } A \text { in letter } \\
\text { list }\end{array}$ & I & \\
\hline & Calculation* & Serial 7 subtractions & 3 & \\
\hline & Repetition* & $\begin{array}{l}\text { Repetition of two complex } \\
\text { sentences }\end{array}$ & 2 & \\
\hline & Verbal fluency** & $\begin{array}{l}>\text { II words beginning with the } \\
\text { letter } F \text { in I minute }\end{array}$ & I & \\
\hline & Abstraction & $\begin{array}{l}\text { Similarities (eg, train and bicycle } \\
=\text { transport) }\end{array}$ & 2 & \\
\hline & Recall* & Recall a list of five words & 5 & \\
\hline & Orientation* & Date, month, year, day, place, city & 6 & \\
\hline & MoCA total score & & 30 & \\
\hline \multirow[t]{7}{*}{$\mathrm{FAB}$} & Similarities & Conceptualization & 3 & Time $10-15$ minutes \\
\hline & Lexical fluency** & Mental flexibility & 3 & \\
\hline & Motor series & Programming & 3 & \\
\hline & $\begin{array}{l}\text { Conflicting } \\
\text { instructions }\end{array}$ & Sensitivity to interference & 3 & \\
\hline & Go-No-Go & Inhibitory control & 3 & \\
\hline & Prehension behavior & Environmental autonomy & 3 & \\
\hline & FAB total score & & 18 & \\
\hline
\end{tabular}

Notes: *ACE-R and MoCA contain MMSE items; **MoCA and FAB same item.

Abbreviations: ACE-R, Addenbrooke's Cognitive Examination - Revised; FAB, Frontal Assessment Battery Scale; MMSE, Mini-Mental State Examination; MoCA, Montreal Cognitive Assessment.

evaluate memory in terms of retention, retrieval, and encoding (eg, the Wechsler Memory Scale (WMS)-Revised ${ }^{45}$ may be employed to distinguish amnesia from dementia in patients). For verbal memory, numerous assessments are used, including the WMS, ${ }^{46}$ Rey Auditory Verbal Learning Test, ${ }^{47}$ Rivermead Behavioral Memory Test (RBMT), ${ }^{48}$ and California Verbal Learning Test. ${ }^{48}$ Memory disorder in elderly dementia patients can be assessed using the Free and Cued Selective Reminding Test. This test aids in distinguishing dementia from normal aging with acceptable accuracy. ${ }^{36}$

Until recently, no specific assessment was developed specifically to assess short-term memory, working memory, and long-term memory impairment following stroke $\mathrm{VaD}$. Thus, evaluating memory in terms of its types to predict stroke effect on memory retrieval is important.

\section{PSMA}

The decline in memory as a result of stroke $\mathrm{VaD}$ and the characterization of memory complaint based on $\mathrm{VaD}$ development can be assessed through a PSMA. This assessment is based on the most popular studies and is a combination of available neuropsychological assessment tests. ${ }^{49,50}$ Memory evaluation is proposed to be associated with memory types. Thus, short-term memory and working memory refer to the perceptual and learning areas of the cognitive domain, which are processed by the frontal lobe. Episodic and semantic long-term memory refers to memory, language, and visuospatial domains, which are processed by the parietal, medial temporal lobe, and hippocampus. Procedural memory refers to the procedural domain and is processed by the cerebellum and basil ganglia. Table 5 describes the proposed PSMA, which achieves this demand. The concept integrated the most usable neuropsychological assessments (MMSE, ACE-R, MoCA, WMS-IV, RBMT, TMT A and B, CDT, FAB, Wechsler Adult Intelligence Scale - Fourth Edition, and others) and reconstructed them to evaluate memory types. ${ }^{50}$

PSMA was designed with inspected administration time of 30 minutes, as illustrated in the Supplementary materials. The test examines the following:

- Orientation: in time and place

- Short-term memory: a seven-digit number, phone number, and postal code

- Working memory: attention and concentration, verbal working memory, and visuospatial working memory

- Explicit long-term memory: episodic memory and semantic memory

- Procedural memory. 


\section{Discussion}

Neuropsychological assessments are used in evaluating and assessing cognitive impairment and dementia. Specific assessment is urgently needed to evaluate different types of memory functionalities after stroke. The present study focused on using available neuropsychological assessments to develop a PSMA scheme based on scientific knowledge, which is available through neuropsychological testing. PSMA may help provide impetus to detect the earliest stages of dementia before significant mental decline. Therefore, efforts are being exerted to use more than one assessment to evaluate cognitive impairment and memory dysfunction. For instance, the MMSE is a brief test with extensive international usage; however, several studies have mentioned that the MMSE alone can be used in a sensitive test to detect cognitive impairment, except if cutoff is increased or combined with other neuropsychological tests. ${ }^{51,52}$ Therefore, the MMSE was used with MoCA and ACE-R to detect MCI because the last two assessments are used to assess early stages of dementia and executive function, as well as identify frontal subcortical infarction..$^{50,53,54}$ In addition, ACE-R has good sensitivity for dementia, whereas MoCA is specifically used in MCI screening. Moreover, TMT, Stroop, and CDT tests can be used with the MMSE to evaluate frontal lesion verbal fluency, and visuospatial skills can be evaluated through Rey Osterrieth figure recall. FAB has been reported to identify frontal temporal lobe dysfunction. ${ }^{55}$ MMSE, ACE-R, MoCA, and FAB characteristics are shown in Table 6 . It can be noticed from the table that the administration time ranged from 35-45 minutes for four assessments. The PSMA administration time was reduced approximately to 30 minutes. PSMA has been designed to incorporate more than one neuropsychological assessment to evaluate short-term, working, and long-term memory with less time consumed compared with multiple test usage. Using more than one assessment to evaluate patient mentality takes a longer time, resulting in patient difficulty in concentrating on the assessment items. PSMA evaluates the cognitive domain and focuses on memory types that are affected by $\mathrm{VaD}$.

\section{Conclusion}

Currently, no specific neuropsychological assessment to assess memory in terms of its types exists. This article provides an overview of the effects of stroke on the brain and on cognitive impairment, including memory evaluation with the most commonly used neuropsychological tests. The article proposes a PSMA to assess different types of memory based on the available assessments. It likewise uses the widely available neuropsychological assessments to study the association between memory as a part of cognitive domain and cognitive impairment, which lead to memory decline in the period following stroke onset.

\section{Disclosure}

The authors declare that there are no conflicts of interest in this work.

\section{References}

1. Cullen B, O’Neill B, Evans JJ, Coen RF, Lawlor BA. A review of screening tests for cognitive impairment. J Neurol Neurosurg Psychiatry. 2007;78(8):790-799.

2. Leys D, Hénon H, Mackowiak-Cordoliani M-A, Pasquier F. Poststroke dementia. Lancet Neurol. 2005;4(11):752-759.

3. Cumming TB, Marshall RS, Lazar RM. Stroke, cognitive deficits, and rehabilitation: still an incomplete picture. Int J Stroke. 2013;8(1):38-45.

4. Mohr JP. Stroke: Pathophysiology, Diagnosis, and Management. Elsevier Health Sciences; 2004.

5. Sahathevan R, Brodtmann A, Donnan GA. Dementia, stroke, and vascular risk factors: a review. Int J Stroke. 2012;7(1):61-73.

6. Iemolo F, Duro G, Rizzo C, Castiglia L, Hachinski V, Caruso C. Pathophysiology of vascular dementia. Immun Ageing. 2009;6(1):13.

7. Sibolt G, Curtze S, Melkas S, et al. Poststroke dementia is associated with recurrent ischaemic stroke. J Neurol Neurosurg Psychiatry. 2013; 84(7):722-726.

8. Brott T, Adams H, Olinger CP, et al. Measurements of acute cerebral infarction: a clinical examination scale. Stroke. 1989;20(7):864-870.

9. Demarin V, Zavoreo I, Kes VB. Carotid artery disease and cognitive impairment. J Neurol Sci. 2012;322(1-2):107-111.

10. Sacco RL, Adams R, Albers G, et al; American Heart Association/ American Stroke Association Council on Stroke; Council on Cardiovascular Radiology and Intervention; American Academy of Neurology. Guidelines for prevention of stroke in patients with ischemic stroke or transient ischemic attack: a statement for healthcare professionals from the American Heart Association/American Stroke Association Council on Stroke: co-sponsored by the Council on Cardiovascular Radiology and Intervention: the American Academy of Neurology affirms the value of this guideline. Circulation. 2006;113(10):e409-e449.

11. Foreman B, Claassen J. Quantitative EEG for the detection of brain ischemia. Crit Care. 2012;16(2):216.

12. Donovan NJ, Kendall DL, Heaton SC, Kwon S, Velozo CA, Duncan PW. Conceptualizing functional cognition in stroke. Neurorehabil Neural Repair. 2008;22(2):122-135.

13. Borson S, Frank L, Bayley PJ, et al. Improving dementia care: the role of screening and detection of cognitive impairment. Alzheimers Dement. 2013;9(2):151-159.

14. Snaphaan L, de Leeuw F-E. Poststroke memory function in nondemented patients: a systematic review on frequency and neuroimaging correlates. Stroke. 2007;38(1):198-203.

15. McVeigh C, Passmore P. Vascular dementia: prevention and treatment. Clin Interv Aging. 2006;1(3):229.

16. Ruitenberg A, Ott A, van Swieten JC, Hofman A, Breteler MM. Incidence of dementia: does gender make a difference? Neurobiol Aging. 2001;22:575-580.

17. Jacova C, Kertesz A, Blair M, Fisk JD, Feldman HH. Neuropsychological testing and assessment for dementia. Alzheimer Dement. 2007;3(4): 299-317.

18. Korczyn AD, Vakhapova V, Grinberg LT. Vascular dementia. J Neurol Sci. 2012;322(1-2):2-10.

19. Ankolekar S, Geeganage C, Anderton P, Hogg C, Bath PM. Clinical trials for preventing post stroke cognitive impairment. J Neurol Sci. 2010;299(1-2):168-174. 
20. Winblad B, Palmer K, Kivipelto M, et al. Mild cognitive impairment beyond controversies, towards a consensus: report of the International Working Group on Mild Cognitive Impairment. J Intern Med. 2004; 256(3):240-246

21. Andrade C, Radhakrishnan R. The prevention and treatment of cognitive decline and dementia: an overview of recent research on experimental treatments. Indian J Psychiatry. 2009;51(1):12-25.

22. Sheng B, Cheng LF, Law CB, Li HL, Yeung KM, Lau KK. Coexisting cerebral infarction in Alzheimer's disease is associated with fast dementia progression: applying the National Institute for Neurological Disorders and Stroke/Association Internationale pour la Recherche et 1'Enseignement en Neurosciences Neuroimaging Criteria in Alzheimer's Disease with Concomitant Cerebral Infarction. J Am Geriatr Soc. 2007;55(6):918-922.

23. Jack CR Jr, Albert M, Knopman DS, et al. Introduction to revised criteria for the diagnosis of Alzheimer's disease: National Institute on Aging and the Alzheimer Association workgroups. Alzheimers Dement. 2011; 7(3):257-262.

24. Albert MS, DeKosky ST, Dickson D, et al. The diagnosis of mild cognitive impairment due to Alzheimer's disease: recommendations from the National Institute on Aging-Alzheimer's Association workgroups on diagnostic guidelines for Alzheimer's disease. Alzheimers Dement. 2011;7(3):270-279.

25. McKhann GM, Knopman DS, Chertkow H, et al. The diagnosis of dementia due to Alzheimer's disease: Recommendations from the National Institute on Aging-Alzheimer's Association workgroups on diagnostic guidelines for Alzheimer's disease. Alzheimers Dement. 2011;7(3):263-269.

26. Sperling RA, Aisen PS, Beckett LA, et al. Toward defining the preclinical stages of Alzheimer's disease: recommendations from the National Institute on Aging-Alzheimer's Association workgroups on diagnostic guidelines for Alzheimer's disease. Alzheimers Dement. 2011;7(3):280-292.

27. Association AP. Diagnostic and statistical manual of mental disorders fourth edition. Washington, DC: American Psychiatric Association; 1994.

28. Hughes CP, Berg L, Danziger WL, Coben LA, Martin RL. A new clinical scale for the staging of dementia. Br J Psychiatry. 1982;140(6) 566-572.

29. Folstein MF, Folstein SE, McHugh PR. Mini-mental state. A prac-32. 1998.

30. D’Esposito M. Chapter 11. Working memory. In: Goldenberg G, Miller BL, editors. Handbook of Clinical Neurology. Volume 88. Elsevier; 2008:237-247

31. Buckner RL. Memory and executive function in aging and AD: multiple factors that cause decline and reserve factors that compensate. Neuron. 2004;44(1):195-208.

32. Lim C, Alexander MP. Stroke and episodic memory disorders. Neuropsychologia. 2009;47(14):3045-3058

33. Snaphaan L, Rijpkema M, van Uden I, Fernandez G, de Leeuw FE. Reduced medial temporal lobe functionality in stroke patients: a functional magnetic resonance imaging study. Brain. 2009;132(Pt 7): 1882-1888.

34. Planton M, Peiffer S, Albucher JF, et al. Neuropsychological outcome after a first symptomatic ischaemic stroke with "good recovery". Eur J Neurol. 2012;19(2):212-219.

35. Cooper S, Greene JD. The clinical assessment of the patient with early dementia. J Neurol Neurosurg Psychiatry. 2005;76(Suppl 5):v15-v24.
36. Pasquier F. Early diagnosis of dementia: neuropsychology. J Neurol. 1999;246(1):6-15.

37. Smith T, Gildeh N, Holmes C. The Montreal Cognitive Assessment: validity and utility in a memory clinic setting. Can J Psychiatry. 2007; 52(5):329-332.

38. Mathuranath P, Nestor P, Berrios G, Rakowicz W, Hodges J. A brief cognitive test battery to differentiate Alzheimer's disease and frontotemporal dementia. Neurology. 2000;55(11):1613-1620.

39. Amodio P, Wenin H, Del Piccolo F, et al. Variability of trail making test, symbol digit test and line trait test in normal people. A normative study taking into account age-dependent decline and sociobiological variables. Aging Clin Exp Res. 2002;14(2):117-131.

40. Shulman KI. Clock-drawing: is it the ideal cognitive screening test? Int J Geriatr Psychiatry. 2000;15(6):548-561.

41. Caffarra P, Vezzadini G, Dieci F, Zonato F, Venneri A. Rey-Osterrieth complex figure: normative values in an Italian population sample. Neurol Sci. 2002;22(6):443-447.

42. Carlesimo G, Caltagirone C, Gainotti G, et al. The Mental Deterioration Battery: normative data, diagnostic reliability and qualitative analyses of cognitive impairment. Eur Neurol. 1996;36(6):378-384.

43. Dubois B, Slachevsky A, Litvan I, Pillon B. The FAB: a frontal assessment battery at bedside. Neurology. 2000;55(11):1621-1626.

44. Roth M. CAMDEX-R: the Cambridge examination for mental disorders of the elderly. Cambridge University Press; 1998.

45. Wechsler D. Wechsler Memory Scale - Revised. San Antonio, TX: Psychological Corporation; 1987.

46. Wechsler D. Wechsler memory scale. New York: Psychological Corporation; 1945.

47. Osterrieth PA. Le test de copie d'une figure complexe. Arch Psychol. 1944;30:206-356.

48. Wilson BA, Cockburn J, Baddeley AD. The Rivermead Behavioural Memory Test. Suffolk, UK: Thames Valley Test Company; 1991.

49. Pendlebury ST, Mariz J, Bull L, Mehta Z, Rothwell PM. MoCA, ACE-R, and MMSE Versus the National Institute of Neurological Disorders and Stroke - Canadian Stroke Network Vascular Cognitive Impairment Harmonization Standards Neuropsychological Battery After TIA and Stroke. Stroke. 2012;43(2):464-469.

50. Bagnoli S, Failli Y, Piaceri I, et al. Suitability of neuropsychological tests in patients with vascular dementia (VaD). J Neurol Sci. 2012; 322(1-2):41-45.

51. Moulaert VR, Verbunt JA, van Heugten CM, Wade DT. Cognitive impairments in survivors of out-of-hospital cardiac arrest: a systematic review. Resuscitation. 2009;80(3):297-305.

52. Cao M, Ferrari M, Patella R, Marra C, Rasura M. Neuropsychological findings in young-adult stroke patients. Arch Clin Neuropsychol. 2007; 22(2):133-142.

53. Sikaroodi H, Yadegari S, Miri SR. Cognitive impairments in patients with cerebrovascular risk factors: a comparison of Mini Mental Status Exam and Montreal Cognitive Assessment. Clin Neurol Neurosurg. 2013;115(8):1276-1280.

54. Kandiah N, Wiryasaputra L, Narasimhalu K, et al. Frontal subcortical ischemia is crucial for post stroke cognitive impairment. J Neurol Sci. 2011;309(1-2):92-95.

55. Bagnoli S, Failli Y, Piaceri I, et al. Suitability of neuropsychological tests in patients with vascular dementia (VaD). J Neurol Sci. 2012; 322(1):41-45.

56. Summers D, Malloy R. CT and MR imaging in the acute ischemic stroke patient: a nursing perspective. J Radiol Nurs. 2011;30(3):104-115. 


\section{Supplementary materials}

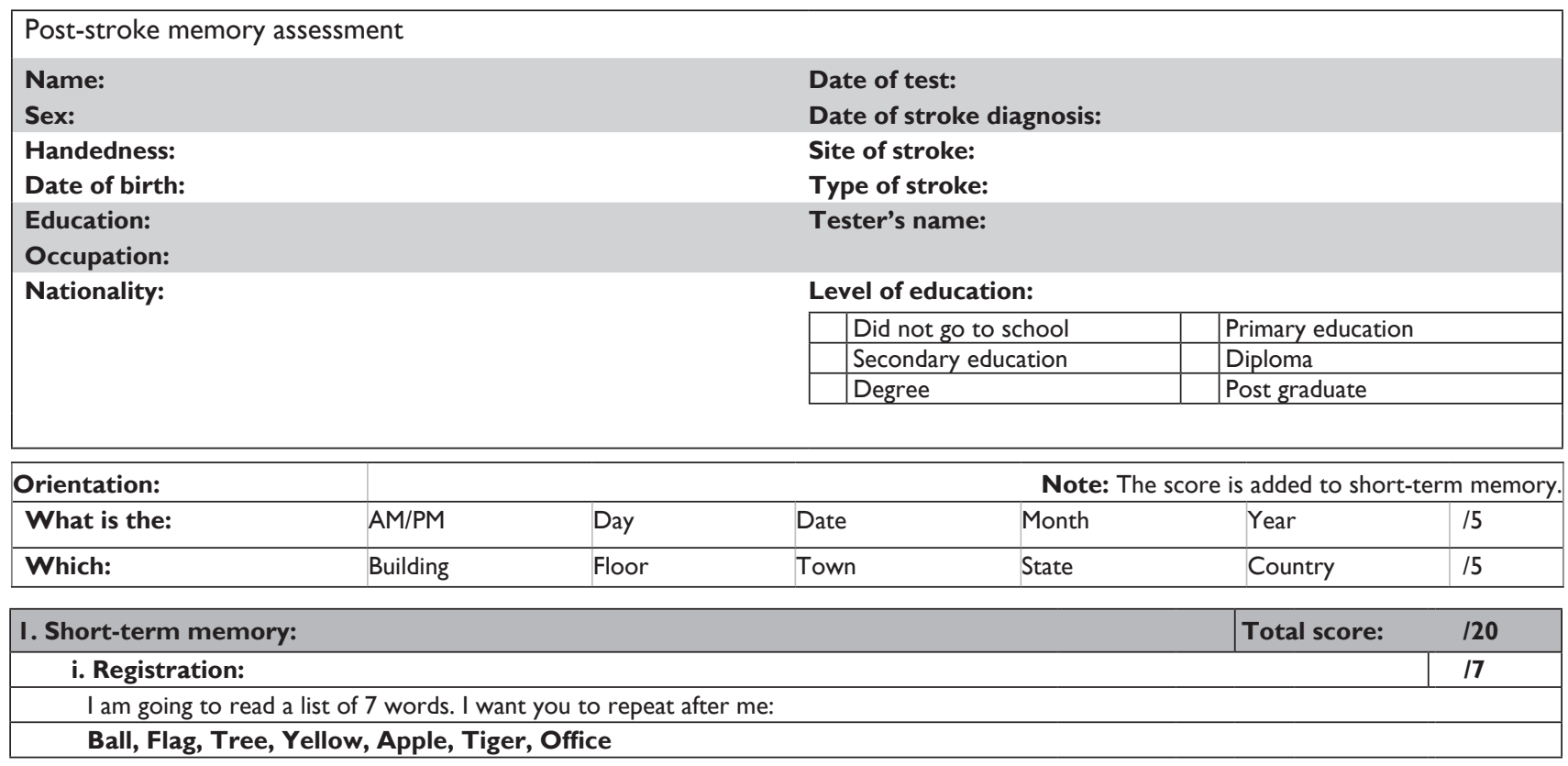

\begin{tabular}{|l|l|}
\hline ii. 7 digits number: & /I \\
\hline I am going to say a series of numbers for you to remember. \\
When I am finished, I want you to select which group I said: \\
7 digits number: $8-6-0-2-9-I-7$ \\
\hline I. 8-6-0-5-9-I-7 \\
\hline 2. 8-0-6-2-4-I-7 \\
\hline 3. 8-6-0-2-9-I-7 \\
\hline 4. 8-6-2-0-4-I-7 \\
\hline 5. 8-6-0-5-4-I-7 \\
\hline $6-0-6-2-9-I-7$ \\
\hline
\end{tabular}

iii. The phone number and postal code:

I am going to say a phone number and postal code for you to remember.

When I am finished, I want you to repeat what I said:

Postal code: 00964

The phone number is: 5463279

\section{Working memory:}

A. Attention and concentration:

i. Number forward

II

I am going to read a list of 5 numbers. I want you to repeat them in the forward order.

2-I-8-5-4

ii. Number backward

I am going to read a list of 3 numbers. I want you to repeat them in the backward order.

7-4-2

iii. Serial subtraction

Serial 7 subtractions are starting at 100 .

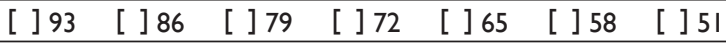

Notes: 4 or 5 correct subtractions: 3 pts, 2 or 3 correct: 2 pts, I correct: I pt, 0 correct: 0 pt.

iv. Alternating trail making

Join the following circles as in the example.

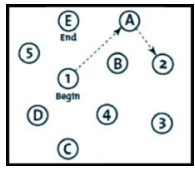




\section{v. Color test:}

I am going to show you a list of color words that are printed in ink colors unrelated to the printed words. I want you to name the color of the printed word not to read the word.

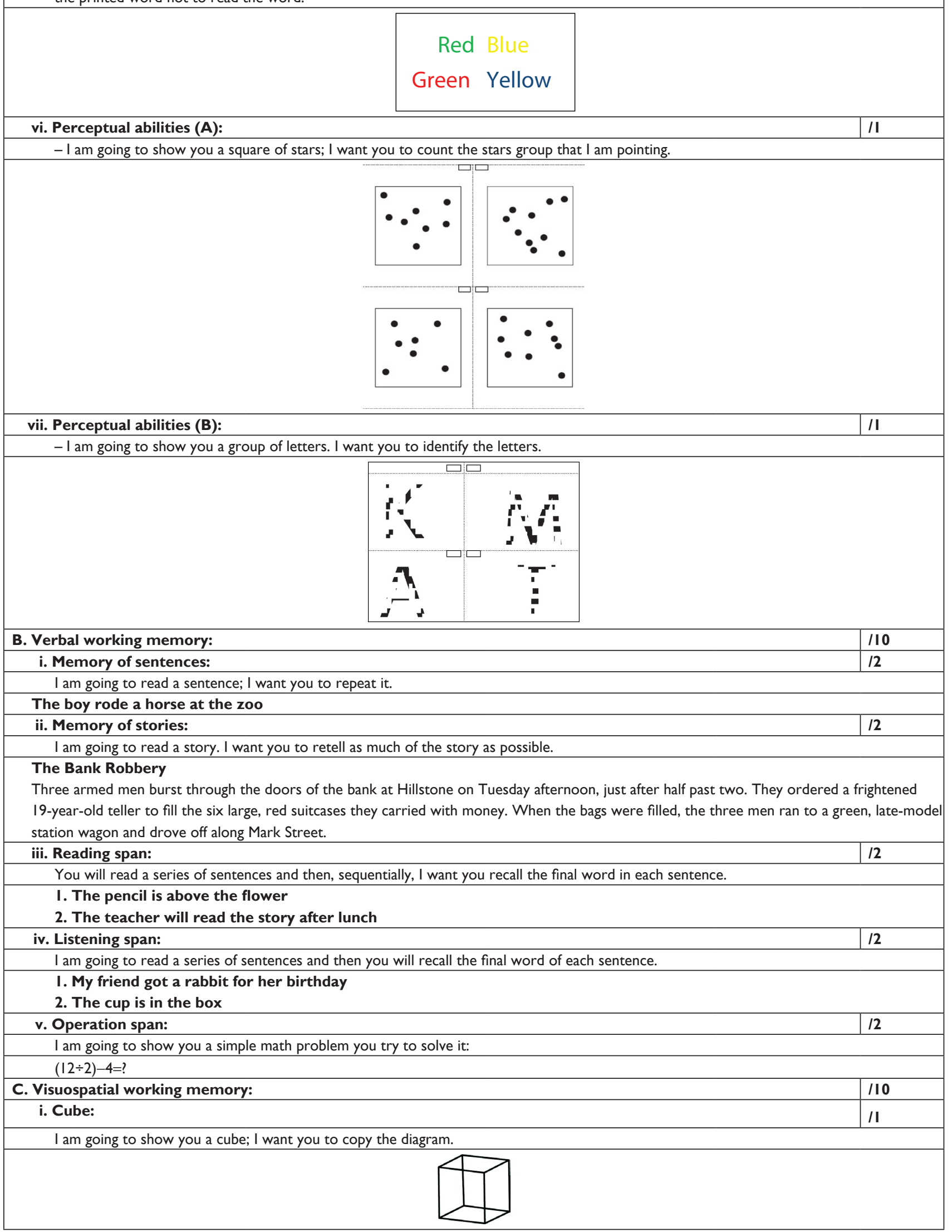

(Continued) 
ii. Clock:

Ask the subject to draw clock (Ten past eleven)
[ ] counter
[ ] number
[ ] hands

iii. Mazes memory:

II

I am going to show you a maze. I want you to follow the red line in the maze with your finger and then draw the exact route that was just observed on an identical, but empty, maze.

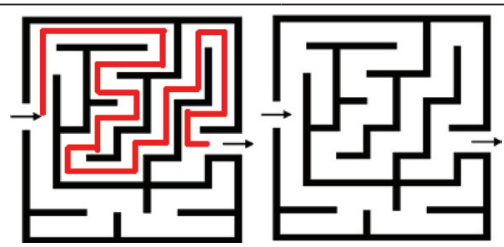

iv. Visual recognition cards:

I am going to show you three cards in two lines, I want you to join the same cards together.

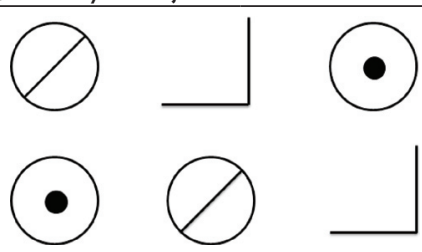

\section{Explicit long-term memory:}

Total score:

140

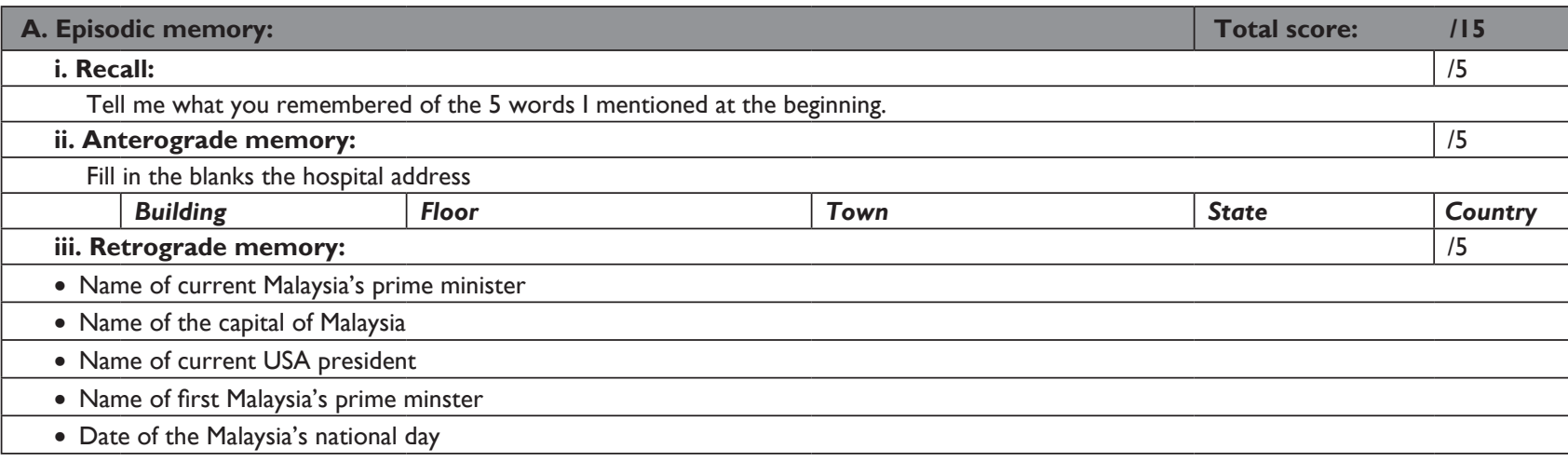

\section{B. Semantic memory:}

Total score:

120

i. Verbal fluency (lexical fluency)

Name maximum numbers of words in one minute that are begin with the letter $F$.

Note: $\mathrm{N} \geq \mathrm{I}$ I words.

ii. Language

I. Repetition:

Repeat:

I only know that John is the one to help today.

The cat always hid under the couch when dogs were in the room.

\section{Naming}

Ask the subject the name of the following pictures:

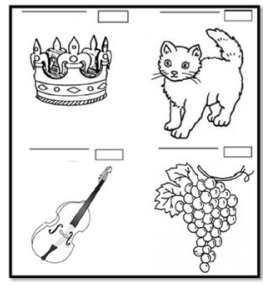

3. Comprehension:

Using the picture above, ask the subject to:

- Point to the one associate to the monarchy 
- Point to the one which is a mammal

- Point to the one which is a musical instrument

- Point to the one which is a fruit

4. Reading:

Ask the subject to read the following words:

Sew, Pint, Soot, Height

5. Writing:

I am going to read words; I want you to write the following:

Blue, England, Yellow, Italy

4. Procedural memory:

Total score:

110

Ask the subject to:

- Dial a phone number

- Fold the paper into two sides

Delayed recall episodic memory:

Total score:

15

Ask "Now tell me what you remember of the 5 words I mentioned at the beginning".

\begin{tabular}{|c|c|c|c|}
\hline & & Sub scores & Total scores \\
\hline \multirow{4}{*}{$\begin{array}{l}\text { Short-term } \\
\text { memory }\end{array}$} & Orientation & $/ 10$ & \multirow[t]{4}{*}{$/ 20$} \\
\hline & Registration & 17 & \\
\hline & 7 digits number & II & \\
\hline & Phone no and postal code & 12 & \\
\hline \multirow[t]{3}{*}{$\begin{array}{l}\text { Working } \\
\text { memory }\end{array}$} & $\begin{array}{l}\text { Attention and } \\
\text { concentration }\end{array}$ & 110 & \multirow[t]{3}{*}{130} \\
\hline & Verbal WM & 110 & \\
\hline & Visuospatial WM & $/ 10$ & \\
\hline \multirow{2}{*}{$\begin{array}{l}\text { Long-term } \\
\text { memory }\end{array}$} & Episodic memory & $/ 15$ & \multirow[t]{2}{*}{135} \\
\hline & Semantic memory & $/ 20$ & \\
\hline \multirow{2}{*}{$\begin{array}{l}\text { Procedural } \\
\text { memory }\end{array}$} & Dial a phone number & 15 & \multirow[t]{2}{*}{110} \\
\hline & Fold the paper into two sides & 15 & \\
\hline Episodic & Delay recall & 15 & 15 \\
\hline
\end{tabular}

Neuropsychiatric Disease and Treatment

\section{Publish your work in this journal}

Neuropsychiatric Disease and Treatment is an international, peerreviewed journal of clinical therapeutics and pharmacology focusing on concise rapid reporting of clinical or pre-clinical studies on a range of neuropsychiatric and neurological disorders. This journal is indexed on PubMed Central, the 'PsycINFO' database and CAS,

and is the official journal of The International Neuropsychiatric Association (INA). The manuscript management system is completely online and includes a very quick and fair peer-review system, which is all easy to use. Visit http://www.dovepress.com/testimonials.php to read real quotes from published authors.

Submit your manuscript here: http://www.dovepress.com/neuropsychiatric-disease-and-treatment-journal 